\title{
Performance Evaluation of Marine Industries Based on Eco-Economy
}

\author{
http://dx.doi.org/10.3991/ijoe.v9iS2.2603 \\ Minli Gong, Yanqing Qi \\ School of Management, Zhejiang Ocean University, Zhoushan, China
}

\begin{abstract}
An assessment framework is made to evaluate the performance factors of marine industries from the perspective of eco-economics by means of the AHP and the Delphi methods. Results are as follows: Performance assessment index of marine industries is decided by ecological performance, economic performance and social performance with ecological index taking priority over economic index; the efficiency of economy output and valuecreating are preferred in the pursuit of low energyconsuming and less polluting marine industries; and in the near future, marine industries will make the greatest contribution to employment.
\end{abstract}

Index Terms-eco-economy, marine industries, performance, evaluation, solution

\section{INTRODUCTION}

It is of great necessity to treasure the scarcity of marine resources and keep the coordination and balance between the marine economic growth and marine ecological environment so as to protect the marine environment, make full use of marine resources, and the development of Marine Industry should discard the old mode of treatment after pollution. In light of the above consensus, it is a challenging and rewarding research project to evaluate the performance of marine industry, which aims to build an assessment index system to assess the impacts of marine industry on regional economy, community and environment from the perspectives of economy, society and environment for the sake of sustainable development. By taking marine resources exploitation, pollution and some others as indexes of social development, calculated as cost, this economy-society-environment assessment index system makes a positive and quantitative survey on the contributions marine industry makes to the overall development, industrial structure, technology advancement, social welfare and ecology. As a result, social performance and ecological performance turn to be important, indispensable to the performance assessment of marine industry. At present, the performance of marine industry has been approached mainly from the single perspective of economic performance, whereas comprehensive research from multi-perspectives of economic performance, social performance and ecological performance is rarely conducted. Based on the previous research achievements, an attempt is made in this paper to build a comprehensive performance assessment system, which may serve as a theoretical foundation and a way to measure and compare the impact of various marine industries on the regional economy.

\section{RESEARCH REVIEW}

With our access to the literature, we have found few research reports directly on comprehensive performance assessment of marine industry, but some on the following related topics such as marine industry assessment, marine industry competitiveness assessment and sustainable development assessment of marine economy.

Assessments of the competitiveness of marine industry and the sustainable development of marine economy are two distinctive assessment approaches to marine industry from the different angles with the emphasis of their own. Marine industry competitiveness refers to the competence owned by a certain section of marine industry in a country or region to compete against its counterparts in other countries or regions in such fields as talents, capital, internationalization level, institution, sci-tech level, productivity, meeting market demand, and keeping profits. Such an assessment highlights the comparative advantage and disadvantage of a certain region, an approach in favour of horizontal comparison. Assessments of marine industry's competence for sustainable development aims to evaluate marine industry's potentials for future development in addition to its sustainability by encompassing the indexes of various aspects of the region such as resources, environment, economy, community and technology with resource and environment as its focus, preferable for vertical comparison.

Comprehensive performance assessment of marine industry tends to evaluate the performance of the branches of marine industry in a certain region within the framework of comprehensive assessment index system. As a result, comparison may be made between industries and the comprehensive performance value of each industry achieved, which is a crucial reference for making decisions to adjust industrial structure, to select the leading industry, or to reinforce the industry. Competence assessment index system differs slightly from competitiveness assessment index system, since, for instance, such public factors as regional resource endowment and infrastructure are deemed as improper indexes for comprehensive performance assessment index system while others might be incorporated in the system for reference. ${ }^{[1]-[13]}$

\section{INDEX SYSTEM CONSTRUCTION}

A comprehensive performance assessment index system for marine industry is constructed in this paper to strike a balance and coordination between economy, ecology and community for the sake of sustainable development with sustainable development, systema- 
tises, dynamics, comprehensiveness and overall benefits as its guiding principles.

\section{A. Index selection}

A two-levelled comprehensive performance assessment index system is designed based on the sustainable development theory and taking into account the features of marine industry: Level A refers to the comprehensive performance of marine industry whereas Level B consists of economic performance, social performance and ecological performance; indexes on Level B are subdivided into 10 indicators (TABLE I ).

\section{1) Economic subsystem}

Economic performance refers to the pursuit of maximum economic benefits at the minimal labour cost, which can be measured by production scale, input and output efficiency and production efficiency.

Total output value refers to the total value of all products made in marine industry within a certain period of time, which reflects the production scale of marine industry. The higher the index shows, the larger the production scale is.

Formula: total output value $=$ time $\times$ products output $\mathrm{x}$ sale price

Added value refers to the balance of the total results of all production activities minus the value of material and labour consumed or transferred in the production, which stands for value added in the production, signifying the contribution of marine industry to GDP.

Formula: added value $=$ output-intermediate input

The overall labour productivity refers to the average output each worker makes in a time unit calculated by the product value index, which reflects the productivity. The bigger the index value is, the higher the labour productivity.

Formula: overall labour productivity = added value / number of staff

\section{2) Social subsystem}

Social performance refers to the contribution of industrial development to social science and technology, politics, culture and other fields. It can be measured by the four aspects of the employment number, talents number, investment on science and technology, and safe production rate.

Employment number: It reflects the contribution marine industry make to the employment of the region.

Talent rate: Talent refers to the people who have mastered certain professional knowledge or special skills, and can make contribution to the community by taking creative jobs. They are the workers with high quality and competence in human resources. Talent rate reflects the comprehensive quality of the industry employees, affecting the long-term stable and healthy development of society and economy.

Formula: talent rate $=$ talent number/the number of employees

Investment on science and technology: It signifies the contribution of the investment on science and technology to the progress of social science and technology.

Safe production rate: Enterprises should take their social responsibility to ensure life safety of the employees.
TABLE I.

COMPREHENSIVE PERFORMANCE ASSESSMENT INDEX SYSTEM FOR MARINE INDUSTRY

\begin{tabular}{|c|c|c|}
\hline Overall layer & Rule layer & Index layer \\
\hline \multirow{10}{*}{$\begin{array}{l}\text { Comprehen- } \\
\text { sive per- } \\
\text { formance of } \\
\text { marine } \\
\text { industry(A) }\end{array}$} & \multirow{3}{*}{$\begin{array}{c}\text { Economic } \\
\text { subsystem (B1) }\end{array}$} & Total output value (C11) \\
\hline & & Added value (C12) \\
\hline & & Overall labour productivity (C13) \\
\hline & \multirow{4}{*}{$\begin{array}{l}\text { Social subsystem } \\
\text { (B2) }\end{array}$} & employment(C21) \\
\hline & & Talent rate (C22) \\
\hline & & $\begin{array}{l}\text { Marine science and technology } \\
\text { input } \\
\text { (C23) }\end{array}$ \\
\hline & & Safe production rate (C24) \\
\hline & \multirow{3}{*}{$\begin{array}{c}\text { Ecological } \\
\text { subsystem (B3) }\end{array}$} & $\begin{array}{l}\text { Energy consumption per ten } \\
\text { thousand Yuan output (C31) }\end{array}$ \\
\hline & & $\begin{array}{l}\text { Waste emission per ten thousand } \\
\text { Yuan output (C32) }\end{array}$ \\
\hline & & $\begin{array}{l}\text { investment on } \\
\text { protection (C33) }\end{array}$ \\
\hline
\end{tabular}

TABLE II.

SCALE AND SIGNIFICANCE

\begin{tabular}{|c|l|}
\hline Scale & \multicolumn{1}{|c|}{ Meaning } \\
\hline 1 & Index i compared with index j, both are equally important \\
\hline 3 & $\begin{array}{l}\text { compared with Index j, Index i is slightly more important } \\
\text { than index j }\end{array}$ \\
\hline 5 & $\begin{array}{l}\text { compared with Index j, Index i is obviously more } \\
\text { important than index j }\end{array}$ \\
\hline 7 & $\begin{array}{l}\text { compared with Index j, Index i is strongly more impor- } \\
\text { tant than index j }\end{array}$ \\
\hline 9 & $\begin{array}{l}\text { compared with Index j, Index i is extremely more } \\
\text { important than index j }\end{array}$ \\
\hline $2,4,6,8$ & $\begin{array}{l}\text { Median of Two adjacent judgment, Importance is the } \\
\text { transition between the judgment }\end{array}$ \\
\hline $\begin{array}{l}\text { Inverse } \\
\text { number }\end{array}$ & $\begin{array}{l}\text { Index i compared with Index j gets bij ; Index j compared } \\
\text { with index i gets bji ,bji=1/bij }\end{array}$ \\
\hline
\end{tabular}

Formula: Safe production rate= the safe production in a certain period of days / number of production days in the same period

\section{3) Ecological subsystem}

Ecological benefits can be measured by energy saving, environment pollution and treatment.

Energy consumption per unit output acts as the key index for measuring ecological benefits. Lower energy consumption which each unit output takes indicates that less resources and energy have been consumed and a better ecological benefit achieved.

Formula: unit output energy consumption = comprehensive energy consumption/output

Waste emission per unit output: Waste emission refers to the emission of sewage, waste gas and solid waste. This index reflects the extent to which the industrial development may damage the environment. The less waste each unit output emits, the more friendly the industry is to the environment.

Formula: unit production value - waste emissions = waste emissions total /output value

Environment protection investment: It shows the concern over the environment protection. More investment 
on the protection suggests more concern over the issue of the environment protection-.

\section{B. Index weight determination \\ 1) A matrix for comparative judgment}

Based on the afore-said index system, we further make the binary comparison between the factors of the lower layer with their counterparts on the higher layer, starting from layer 2 of the hierarchical structure model, and determine the relative correlation/coefficient by the evaluation scale, and establish a judgment matrix accordingly. Experts' $1 \sim 9$ scale scoring and its significance are shown in Table 2.

\section{2) Calculating weight coefficient}

A group of experts are invited to evaluate and score the binary judgement matrix achieved based on the index system. Then, with the aid of judgment index, all the value weights on Layer A and weight value of all factors on Layer B are calculated.

The importance of single factors may be measured by means of square root with the calculation formula as follows:

$$
\begin{aligned}
& \text { The normalized weight coefficient }\left({ }^{W_{i}}\right) \text {, } \\
& W_{i} \text { amounts to: } \\
& \sum_{I=1}^{n} \quad W \quad i=1
\end{aligned}
$$

Then the value weight of all elements between the layers ,Formula for the maximum value of the matrix:

$$
\lambda_{\max }=\frac{1}{n} \sum_{\mathrm{i}=1}^{\mathrm{n}} \frac{(A W)_{\mathrm{i}}}{W_{i}}
$$

Due to the possible one-sidedness of one expert's scoring, ten experts are invited to score. We first check the index weight that each expert scores respectively, and then take the arithmetic mean or geometric mean value of the total weights which all the experts score the same index, and again by normalizing, we get the index weight.

\section{3) Consistency test}

$$
\begin{aligned}
& \text { According to the formula } \mathrm{CI}=\frac{\lambda_{\max }-\mathrm{n}}{\mathrm{n}-1} \\
& \mathrm{CR}=\frac{C I}{R I} \text { and the calculation of each expert's scoring } \\
& \text { of CR, the calculation results are shown in Table } 3 \text {. } \\
& \text { When the calculated CR is less than 0.1, then it can } \\
& \text { pass the conformance test. Finally take the weight of the } \\
& \text { geometric mean to each index of all experts, and then } \\
& \text { standardize them to get the weight of each index. }
\end{aligned}
$$

\section{4) Weight value}

The index weight value of all levels is as follows, which passes the consistency test.

$$
\begin{aligned}
& \mathrm{w}_{\mathrm{A}}=\left(\begin{array}{lll}
0.381 & 0.185 & 0.434
\end{array}\right) \\
& \mathrm{w}_{B 1}=\left(\begin{array}{lll}
0.131 & 0.291 & 0.578
\end{array}\right) \\
& \mathrm{w}_{B 2}=\left(\begin{array}{llll}
0.287 & 0.208 & 0.257 & 0.248
\end{array}\right) \\
& \mathrm{W}_{B 3}=\left(\begin{array}{lll}
0.429 & 0.306 & 0.265
\end{array}\right)
\end{aligned}
$$

TABLE III.

CR VALUE OF EXPERT’S SCORING

\begin{tabular}{|c|c|c|c|c|}
\hline 1 & 2 & 3 & 4 & 5 \\
\hline 0.0079 & 0.056 & 0 & 0.033 & 0.015 \\
\hline 6 & 7 & 8 & 9 & 10 \\
\hline 0 & $\mathbf{0 . 0 4 6}$ & $\mathbf{0}$ & $\mathbf{0}$ & 0 \\
\hline
\end{tabular}

\section{CONCLUSIONS AND SUGgESTIONS}

By the index weight determined by experts'scoring, we can see that the ecological performance has attracted more attention than economic performance, which implies that the various ecological problems of the past development make people increasingly concerned about ecology and desirous of low energy- consuming and lesspolluting industries in the economic development. As for the economic indicators, the weight value of overall labour productivity amounts to 0.578 , much higher than that of total output value and added value, which shows that marine economic output efficiency has been greatly emphasized in terms of the output by each employee; added value is more appreciated than total output value, in another word, priority is given to making new value rather than enhancing economy scale. Although little difference in the weight values is found between the other four social indicators, yet marine industry contributes the most to employment. In ecological indexes, output value per ten thousand Yuan unit has the highest weight value, energy consumption the second highest, while environmental protection investment the lowest. These figures indicate the trend to develop marine industry with low energy consuming and less polluting outcome. Furthermore, low energy-consuming and less polluting development is preferred to the conventional development mode of treatment after pollution,. Below are some strategies and measures we propose for the development of marine industry: Enhance the protection of marine environment. With a clearer mind of marine ecology, we should upgrade circular and ecological economy by forging energy-saving and environmentprotecting industrial structure, development mode and consumption patterns.; Enlarge investment on marine environment protection, keep marine pollution in control, be alert to marine disasters, strengthen ecological environment restoration, and establish benign marine ecosystem[14]with the strict implementation of the policy "Pay for the sea use".

Focus on economic benefits of marine industry. The development of marine industry should adhere to sci-tech backed sea-booming programs, with increasing investment on science and technology and high technology industry encouraged to develop. Efforts should be taken to consolidate the human resources for the development of marine science and technology by attracting more talented people; With marine industry planning marine industry cluster is promoted for the efficient and intensive development, which may bring forth the scale economic effect; Finally, the reliable internal management mechanism should be framed for marine science, so as to improve the industry management.

Optimize marine industry structure. On decision making for development of marine industry, structure optimization should enjoy the same priority as marine economic growth, and when checking and evaluating 
marine economy development, structure and quality, together with comprehensive economic, social and ecological performance value should be considered as key indicators equally important as the indicators of output and speed. Industrial structure should be designed and adjusted to make full advantage of marine resources, suitable for the new trend of industrialization, granting more support to the development of industries with high comprehensive performance value. Speed up the adjustment of fishery structure with the ways found to make more added values to aquatic products. The establishment of sustainable fishing institution can be the solution to the above-mentioned problems: By making a longterm development agenda and establishing an efficient product monitoring system, added value of the fish processing industry will be upgraded.

Measures should be taken to upgrade marine industry and accelerate the gathering of industry such as marine chemicals. By amending policy and regulation for marine industry, it is priority to upgrade ocean oil-gas industry and shipyard and to accelerate the formation of industry cluster, such as the cluster of marine chemical industry. Encourage the development of coastal tourism by attaching importance to investment on the coastal tourism infrastructure, developing more products and extending the industrial chain of coastal tourism, promoting practitioners' human capital and the quality of service, and raising the added value of coastal tourism products.

\section{REFERENCES:}

[1] Wang Y, (2004). The Analysis on Evaluation Index and Measurement of Marine Industry. Ocean Development and Management. 4(14)18-21.

[2] Yu J, Li B, (2007). Research on Evaluation and Improvement of Marine Industry Market Performance: Based on Rabah Amir Model and SCP Mode. Industrial Economics Research, 5(2), 1421.

[3] Sun Y,, Han Z, (2008). Structure Analysis of China's Regional Marine Industry and Discussion on performance evaluation. Ocean Development and Management,3(9), 63-67.

[4] Yin K, (2010). The Joint Decision Measure Model of China's Marine Industry Competitive Power Evaluation .Review of Economic Research, 2(8), 27-37
[5] Liu D, (2011). The Theory and Empirical Research of Regional Marine Industry Competitive Power Evaluation . Ocean Development and Management, 6(7), 90-94

[6] The Establishment of Competitiveness Evaluation System of Shandong Marine Industry . Ocean Development and Management, 8(7), 109-113.

[7] Liu Y.(2011). Marine Industry Competitiveness Research of the Shandong Peninsula Coastal City Based on Cluster Analysis.Ocean Development and Management, 5(6), 71-75.

[8] Di Q, Han Z., Sun Y.(2008). Assessment of Sustainable Development Capability of Marine Economy and Its Application in Liaoning Province. Resources Science, 31(2), 288-294.

[9] Cui M. (2009). The Establishment of Comprehensive Evaluation System of Regional Marine Economic Development. Ocean Development and Management, 8(6), 58-64.

[10] Liu M. (2008). The Evaluation of the Capability of Sustainable Development of Regional marine economy.China Statistics, 8(3), 51-53.

[11] Xu S. (2011). The Establishment of Evaluation Index System of China's Marine Economic Sustainable Development. Ocean Development and Management, 5(3), 65-70.

[12] Lin X. (2011). Comprehensive Evaluation and Empirical Analysis of Sustainable Development Ability of China's Marine economy. Development Research,5(5), 7-12.

[13] Zhang L. (2011). The Enlightenment of Foreign Marine Development Situation to China . Studies in International Technology and Economy, 9(4), 7-12.

[14] Zhang Li. The Enlightenment of Foreign Marine Development Situation to China[J] . Studies in International Technology and Economy, 2006, 9( 4):7-12.

\section{AuTHORS}

Minli Gong is with School of Management, Zhejiang Ocean University, Zhoushan, Professor, 316000, China. (e-mail: gml311@sina.com). She is now with the Department of Marine Industry and Ecological economy.

Yanqing Qi is with School of Management, Zhejiang Ocean University, Zhoushan, A master's graduate students, 316000, China. (e-mail: 740549403@qq.com). She is now with the Department of Marine Industry and Ecological economy.

This article is an extended and modified version of a paper presented at the International Conference on Mechanical Engineering, Automation and Material Science (MEAMS2012), held 22-23 December 2012, Wuhan, China. Received 14 February 2013. Published as resubmitted by the authors 25 March 2013. 